\title{
Future Internet Visions and Research Clusters
}

\section{Gyula Sallai}

Future Internet Research Cooperation Centre, Debrecen;

Inter-University Centre for Telecommunications and Informatics;

Department of Telecommunications and Media Informatics

Budapest University of Technology and Economics

Magyar tudósok krt. 2, H-1117 Budapest, Hungary

e-mail: sallai@tmit.bme.hu

\begin{abstract}
Telecommunications and the Internet are forming an increasingly integrated and global system for processing, storing, transporting information and managing content. At the same time the identification capacity of the Current Internet is running out, Internet architectures are reconsidered for better managing mobility and quality requirements, data handling and security issues, as well as for exploiting the opportunities derived from technological development. The future of the Internet became an important research and standardization area, focusing on service, resource, content and environmental awareness. The paper summarizes the challenges of the Current Internet, draws up the visions and the recent capabilities of the Future Internet, then identifies and clusters the relevant research topics defining the chapters of Future Internet research activity in a layered model from basic research on Internet Science through the Internet Engineering up to Future Internet applications and experiments.
\end{abstract}

Keywords: Future Internet; Future Internet vision; Future Internet research; Internet Science; Internet Engineering; Internet technologies; Future Internet applications

\section{Introduction}

Telecommunications and the Internet are forming more and more an integrated global infrastructure for processing, storing and transporting information and managing content related to locations, people and intelligent devices. This integration process is based on the rapid evolution of the digital technology and the penetration of the Classic Internet concept. The progression towards an integrated telecommunications, information technology and electronic media (TIM) sector has been presented e.g. in [21, 36, 49, 50]:

- The first step was the digitization and integration of network functions within voice communication (telephony), data communication and media communication (broadcasting) sectors, each separated by their content. 
- Secondly, a uniform digital communication technology of various contents and an integrated telecommunications (formally referred to as electronic communications) sector was formed.

- The third step presents the convergence of resources and processes for communications, information processing and storing, and content handling, the emergence of the integrated TIM sector and synergic TIM applications based on IPv4/TCP.

- Recently, in the fourth step the content space is expanding by cognitive and sensory contents, the billions of devices (things) are to be interconnected (Figure 1), and an open Digital Ecosystem is being formed [1, 24, 40, 56, 58].

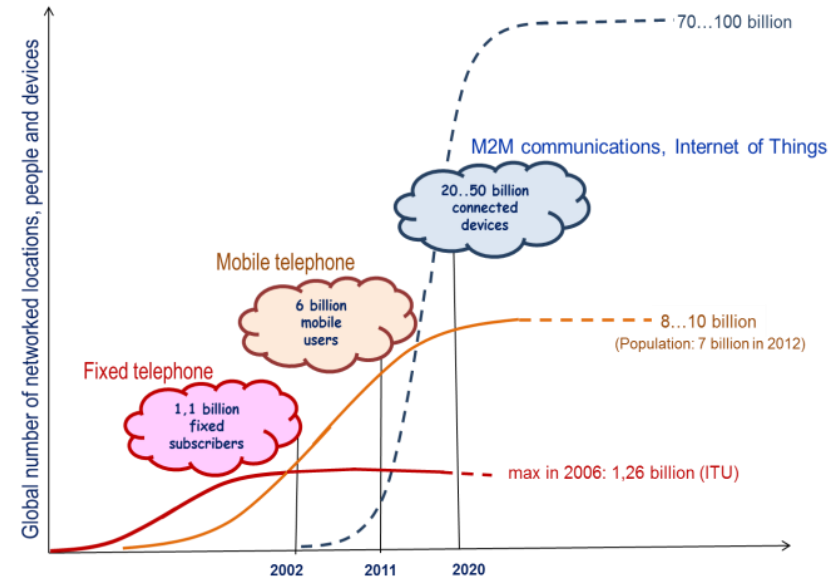

Figure 1

Evolution phases of networking: number of networked locations, people and devices

A horizontally and vertically integrated information (TIM) value chain is shaped (Figure 2), comprising all the layers and services of the intelligent infrastructure of the networked knowledge society, sometimes referred to as Internet infrastructure. At the same time the identification capacity of the Current Internet is running out; Internet architectures are reconsidered for better managing mobility functions, quality requirements and security issues, as well as for exploiting the opportunities derived from the technological advancements and the recent data handling and cognitive concepts. This integration process transforms business and bank spheres, administration, production, agriculture, transport, health, education and knowledge systems, etc., our everyday life. The future networked knowledge society is going to be established on Internet base, but the limitations of the Current Internet must be eliminated.

Recognizing the challenges of the Current Internet and the opportunities and requirements for a more advanced Internet, European Commission supported intensively the research activity on the Future Internet (FI) and initiated the 
organisation of the Future Internet Assemblies (FIAs). Since 2008 ten FIAs were held and four books were issued on the research results $[1,2,3,4]$. This paper collects the challenges and opportunities of the Current Internet, the visionary and recent capabilities of the Future Internet, defines the research goals and spheres, and identifies and clusters the relevant research topics into nine research chapters: from basic research on Internet Science through Internet Engineering up to Future Internet applications and experiments.

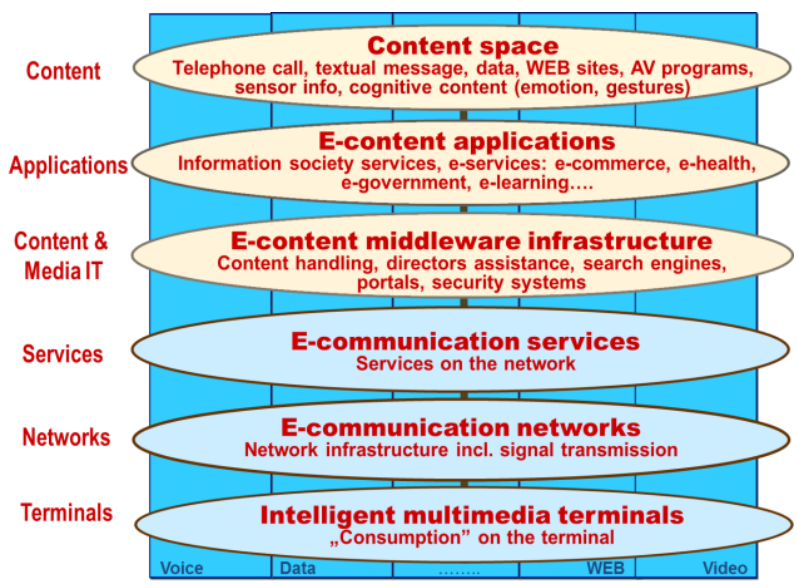

Figure 2

Integrated information value chain:

the layers of intelligent infrastructure of networked knowledge society

\section{Challenges of the Current Internet}

The Internet concept was born with different conditions and goals by "the fathers of the Internet", Vinton G. Cerf and Robert E. Kahn [12] in the seventies. Since then the Internet has become a large global network and we are currently speaking on the Internet age. The original concept of the Internet (TCP/IPv4) has limitations, and there are new societal requirements (mobility, security), while technological developments provide new opportunities and solutions for the challenges.

\section{Limitations of the Current Internet are [1, 2, 3, 4, 44, 60, 62]:}

- The limited identification capacity, the lack of IPv4 address space;

- The essentially private wireline network concept, the lack of an inherent mobile centric network architecture and a scalable efficient network and mobility management; 
- The lack of guaranteed and differentiable quality of services and security (the best effort solutions);

- Energy consumption: the emission of $\mathrm{CO}_{2}$ is increasing due to the increase in network size and usage;

- Application development is slow, inflexible, etc.

New technological opportunities are for managing limitations $[1,2,3,4,38,42$, 44]:

- Advanced wireless/mobile technologies;

- Broadband optical solutions;

- Huge storage capacity, storage efficiency;

- Innovations in material and manufacturing technology, especially in the technology of sensors, CPUs, memories and energy sources;

- Potential opportunities deriving from nanotechnology and biotechnology.

Growth of the Internet's societal role gives rising demands as [2, 3, 4, 23, 33, 58]:

- Anywhere, anytime access (always on);

- Interconnection of devices, objects, sensors (networked 20..100 billion things);

- Expansion of content space with 3D and cognitive contents (gestures, emotion);

- Scalable and customized data and knowledge engineering;

- A lot of human centric, secure, smart applications.

We can conclude that:

- We are witnesses to the radical increase of Internet's size and complexity;

- There is a great technical potential and societal need for significant expansion of applications;

- The penetration of Internet has a fundamental impact on lifestyle and human relations.

\section{Visions of the Future Internet}

The challenges of the Current Internet, the tangible and potential demands and the technical opportunities determine the critical research issues, research objectives, and needs the reconsideration of the Classic Internet concept and the construction of the vision of the Future Internet. 
Figure 3 shows the Future Internet vision based on the scheme of Japan's National Institute of Information and Communications Technology (NICT) [40], and the achievements of the FIA 2011 in Budapest and Poznan, FIA 2012 in Aalborg [2, 3, 57]. NICT prepared the first vision for New-Generation Networks (NWGN) in 2008 focusing on the technology requirements for solving social problems (energy shortage, medical care, crime prevention, technology gap, etc.) and creating new values for achieving a future knowledge society, using the NWGN. Five network targets were identified for an NWGN R\&D strategy, whose scheme was used for the Future Internet and continuously evolved aiming at an intelligent, sustainable world and an innovative, secure society as a generic goal of the Future Internet $[3,51]$. Figure 3 shows two pillars and six targets (objectives), and the desired applications are also indicated. The Classic Internet is aimed at the interconnection of persons and contents. The Future Internet is completed by the interconnection of all sorts of devices and things which involve sensors and actuators to sense or actuate respectively their physical environment. This idea is demonstrated by two pillars referred to as: Internet of People (Media Internet) and Internet of Things (IoT) [52, 56]. The Future Internet aims at a unified infrastructure of communication, computing and storage systems that involves the Internet of people, content, devices and things. The Future Internet should support:

- The drastic increase of the networked infrastructure characteristics (scale, diameter, bandwidth, service set, etc.);

- The expected wide range of networked services with diverse and evolving service requirements;

- The efficient operation and management of all communication, computing and storage resources;

- The concept of the "Internet of Everything", the convergence of the consumer, business and industrial Internets.

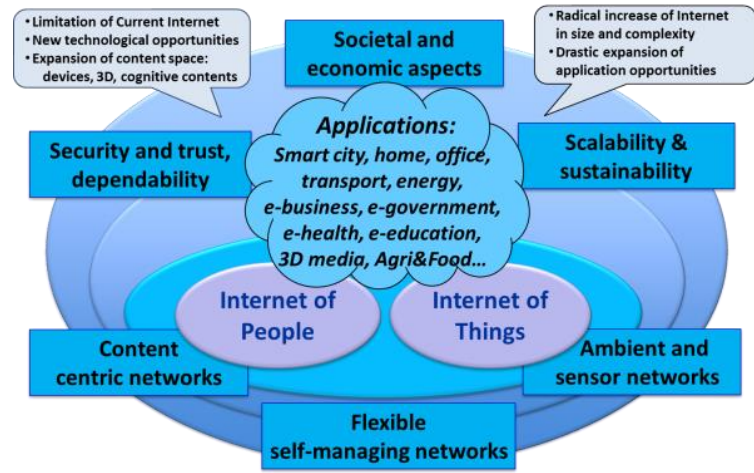

Figure 3

Future Internet vision, based on Japan NICT's NWGN vision, FIA2011 in Budapest and Poznan, and FIA2012 in Aalborg 
Therefore Future Internet research activities primarily focus on network architecture issues to solve challenges in scalability, flexibility and manageability, with special attention to ambient (ubiquitous) and sensor networks (IoT), large amounts of various data (Big Data) generated by the IoT, as well as to content centric multimedia networks and networked 3D content. Internet security, dependability (reliability, accountability, verifiability) and trust as well as sustainability referring to energy awareness (green network) and efficient spectrum usage are also priority issues in the deployment of the Future Internet, and are closely related to the Future Internet vision [42, 57]. Drastic expansion of application opportunities (smart city, home, office, intelligent transport, energy, ebusiness, e-government, e-health, e-education, 3D media, etc.) assisted by the Future Internet Cloud concept [4, 45] and the societal-economic aspects and impacts (e.g. service economy, social interaction, augmented reality, Internet-style innovation) are also significant research targets [57].

A well-established Future Internet vision can be based on the standardization work of the Future Networks (FNs) performed by the International Telecommunication Union Telecommunication Standardization Sector (ITU-T). Driven by the research activities in network virtualization, cloud networking and others $[3,22$, 28, 59, 60], the ITU-T has started the standardization of FNs as networking systems to be deployed in the 2015-2020 timeframe [4, 37]. FN standardization combined two complementary approaches: a top down method starting from objectives and design goals, and a bottom up method starting from relatively matured candidate technologies. Recommendation ITU-T Y.3001 presents the first standard description of FNs [29, 37]. The Future Network is described, like the Future Internet, as an infrastructure that connects and orchestrates the Internet of people, content and systems (i.e. devices, computers, clouds and things). The Recommendation identifies four essential objectives that were not suitably taken into account in the design of current networks. They help to characterize the differences from the current networks. Design goals related to the objectives were also identified as advanced capabilities that are necessary for the realization of FNs. The four objectives described in Y.3001 can be considered the elements of the vision of the Future Internet (Figure 4). They are the followings:

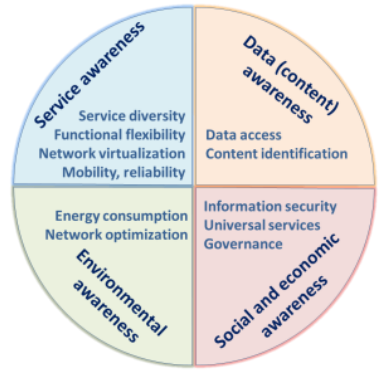

Figure 4

Future Internet vision, based on the standardization work of the Future Networks performed by ITU-T 
- Service awareness: Future network architectures are expected to support not only current services such as e-mail and web browsing, but also emerging services, including mission critical services, by providing additional functionality without drastic increases in communication, computing and storage resources, deployment and operational costs. Thus, these network resources are to be virtualised to allow for their flexible usage by the services (resources awareness, network virtualization concept) [30]. Network virtualization means the process of partitioning the network resources, abstracting the partitions as virtual network resources, and combining them and network functionalities into logically isolated virtual networks. A unified network resources management is also involved. Such a way, multiple virtual networks can be created in a single physical network. Furthermore the network architecture should support advanced mobility features, enhanced reliability and security requirements.

- Data (content) awareness: Communication in current networks is based on the globally unique location identity (ID) and location based routing. If identical contents (data, information) are placed in multiple data locations, they may have the same content ID, and the content can be accessed via a nearest location using content ID based routing. In such a way the handling of a vast amount of data can be optimized [32].

- Environmental awareness: The enormous increase in Internet traffic means increase in energy consumption; hence energy awareness is a key objective. To save energy we should optimize the network to reduce the network capacity and traffic loads, as well as improve the energy efficiency using lower power electronic technology and dynamic control techniques [31].

- Socio-economic awareness: The Internet becomes an essential infrastructure utility; the right to have access to a global network will be one of the fundamental rights in the future. Hence the Future Internet should consider socio-economic objectives as governance issues, e.g. the barrier to enter the market, the lifecycle cost for sustainability and deployment, service universalization, information security, and personal data protection [29].

Figure 5 suggests $a$ vision for the Future Internet, combining the research oriented NWGN vision scheme $[40,51]$ and the standardization oriented FN vision of the ITU-T [29, 37], taking also into account the achievements of the FIA 2013 in Dublin [4]. The Future Internet vision aims at a unified infrastructure of communication, computing and storage resources by integrating the Internet of people and content, devices and things, computers and clouds. Figure 5 demonstrates three concepts (Internet of People, Internet of Things and their unification and extension) as pillars, indicates the smart, high-value applications provided as services in the Cloud, and shows five strategic objectives. The objectives are based on the ones of the NWGN and FN visions, as follows: 
- Scalable, flexible, service aware network means a scalable network architecture with functional flexibility, which can accommodate wide range of services with diverse and evolving requirements;

- Virtual, resource aware network means the virtualization of combined communication, computing and storage resources and a unified efficient network resources management system;

- Data and content awareness embraces goals on content-centric networking, content identification (ID) and efficient handling and usage of the generated Big Data, involving 3D and cognitive contents;

- Sustainability, environmental awareness refers to energy awareness, efficient spectrum usage and any other ecological aspects;

- Intelligent, innovative and secure society, as a generic target of Future Internet, comprises the societal-economic objectives and aspects.

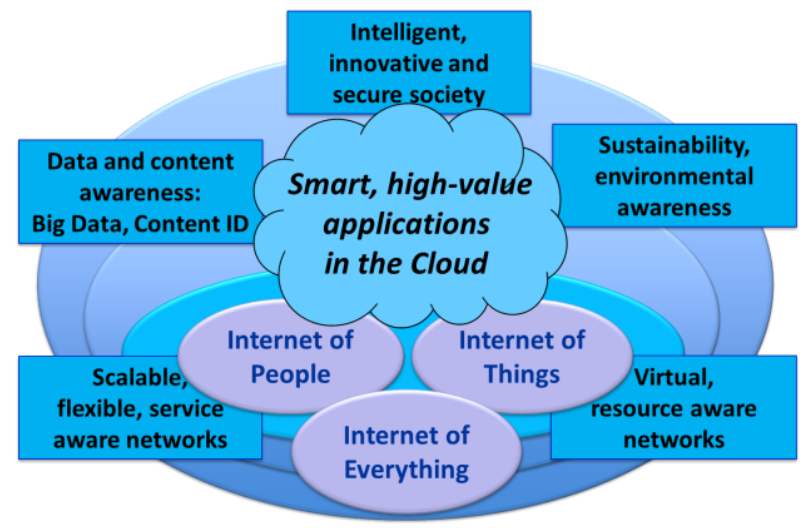

Figure 5

Future Internet vision, combining NWGN and FN visions

\section{Recent Future Internet Capabilities}

Recently, there has been no accepted definition for Future Internet, rather it is described by some capabilities, which do not exist in, or are not typical of the Current Internet. Some new functions created and certain features became obvious in the last some years that are relevant criteria in separating the Current and Future Internet. In the following, eight functions and four features associated with the Future Internet are listed. The lists as a matter of course are open; recently, one or more functions and some of the features became characteristics of the Future Internet solutions. 
A recent list of relevant Future Internet functions is $[2,3,4,19,24,33,40,45,47$, 55, 56]:

1. Identification and interconnection of things, devices, sensors, actuators (Internet of Things);

2. Network architecture intrinsically handling service diversity, mobility, ,anywhere, anytime” data collection, tracking and tracing (Service and mobility centric architectures);

3. Networked data bases: real time access and global organization of huge amount of data, information and multimedia contents (Big Data concept);

4. Content-aware technologies: content selection, distribution, outsourcing and management, content centric networks, content mining;

5. Programmability of networks: virtualized, software-defined networks (SDN);

6. Communicating and managing 3D and cognitive contents, virtual and augmented world;

7. Cloud computing and communications: infrastructure, platform, software, network and communication provided as a service (IaaS, PaaS, SaaS; NaaS, $\mathrm{CaaS})$;

8. Remote collaboration, monitoring and control of physical processes (Tactile Internet).

A list of relevant Future Internet features is [2, 3, 4, 37, 44, 57]:

1. Inherent information security, personal data protection;

2. Managed quality, service-aware architectures and application platforms;

3. Managing the energy needed to transmit bits in the device, equipment and system levels;

4. Personalization: customized solutions and presentation profiles.

Recent capabilities are in good coincidence with the visionary ones, which shows the reality of the vision and the awareness of the research governance.

\section{Clustering Research Themes}

The research goals and spheres can usually be combined into three levels. The Internet is considered a complex networked infrastructure: its common attributes are heavily researched in the frame of Network Science. In general, basic research topics related to the fundamentals of Future Internet, embracing mathematical modelling of large scale networks, cryptography as the theory of security, human and socio-economic characteristics and environmental aspects, legislation and 
governance principles, etc. are collected in Internet Science [23]. Engineering research issues - such as the creation and elaboration of Future Internet technologies, network architectures and protocols, data and content management methods and design procedures - represent the backbone of the Internet applied research, called Internet Engineering [16]. Finally Future Internet experimental research and innovation actions aim at the development of FI-based solutions, smart industrial and community applications, customizable content services, involving their experimentation, demonstration and standardisation issues, referred to as Internet application development [2, 3, 4, 24].

Studying the research themes on the Future Internet in the literature, in particularly on FIAs [1, 2, 3, 4, 53], Working Programme of Horizon 2020 [24] as well as the Hungarian Future Internet research activity, including 132 themes [7, $16,51]$, the relevant research topics can be identified and arranged into main research areas. We define the main research areas as the chapters of Future Internet research activity in a layered model from basic research on Internet Science through Internet Engineering up to Future Internet applications and experiments. Figure 6 shows the nine layered chapters and their main research goals and spheres. Basic research in Internet Science constitutes Chapter 1, the Internet Engineering applied research is divided into five chapters (Chapter $2 \ldots .6$ ), the applications and experiments are comprised of three chapters (Chapter 7, 8 and 9). Figure 6 also indicates the possible relations of the chapters to other research goals and spheres. In the following, the research chapters and their relevant topics (topic ranges as subchapters) are presented.

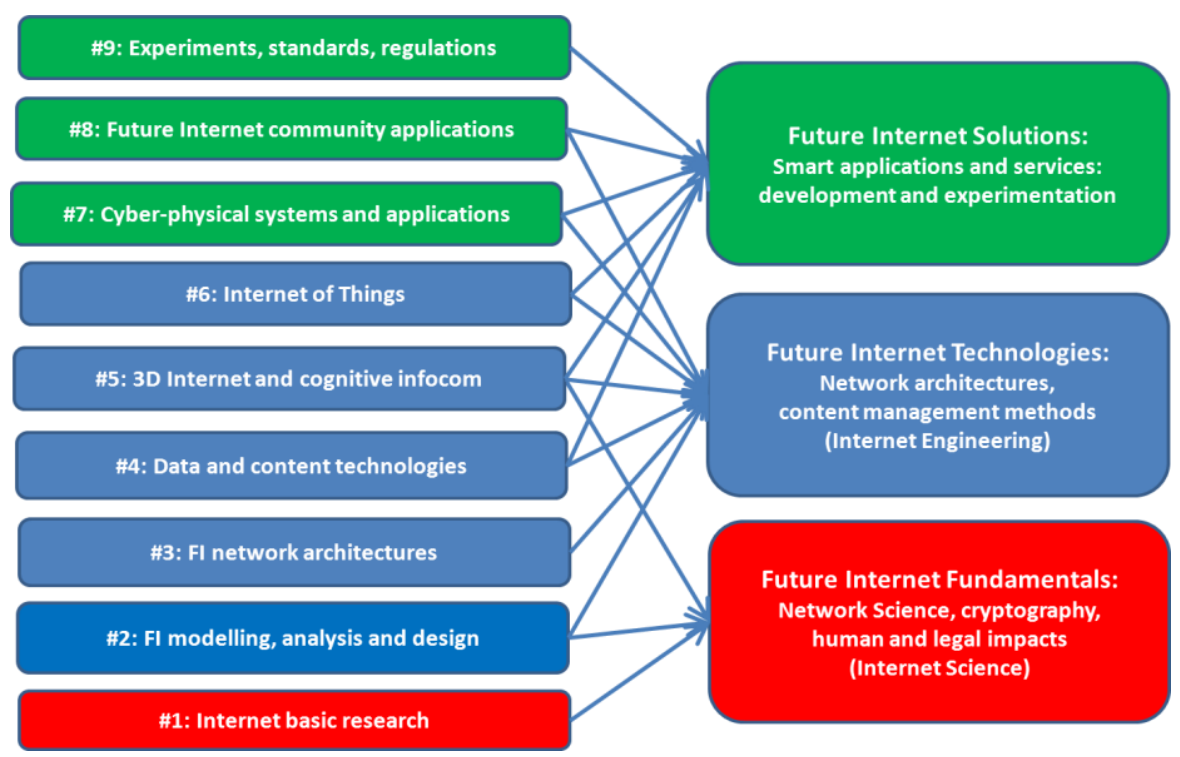

Figure 6

Future Internet research chapters and their relation to research goals 


\section{Chapter 1: Internet basic research (Internet Science).}

Internet Science aims at an integrated and interdisciplinary scientific understanding of Internet networks and their co-evolution with society, embracing all disciplines that study the Internet from any technological or humanistic perspective. Relevant research topics as subchapters are $[6,8,18,23,25,26,35$, 36, 58]:

A) Network science: modelling and investigating large scale networks;

B) Computer science, from computational theory to computer architecture;

C) Basic enabling technologies, as quantum and nanotechnologies, etc.;

D) Cryptography, cyber security;

E) Human aspects: social and behavioural attributes, trust and aversion, cognitive processes, cognitive biases, social networks;

F) Network economics, game theory;

G) Legislation and governance (privacy, data protection, net neutrality...).

Chapter 2: Future Internet modelling, analysis and design.

These research topics target the modelling of the Future Internet enabling infocommunication systems, network concepts and technologies, for analysing their performance, scalability, stability, availability, resilience, quality of service, etc. as well as the elaboration of novel modelling and design paradigms. Relevant topics are as [10, 23, 20, 47, 55]:

A) Network modelling and performance analysis;

B) Queuing systems: traffic analysis and design;

C) Communication systems: advanced modulation, coding, access, spectrum usage;

D) Resource allocation and optimization methods;

E) Investigating networked media services: video streaming, VoIP, IPTV;

F) Survivability techniques, monitoring, failure exploration.

\section{Chapter 3: Future Internet network architectures.}

Novel architectural solutions are needed to meet the societal challenges, which the Current Internet may not be able to support sufficiently. This central research area focuses on new network architectures and protocols, virtualization of resources, mechanism enhancements, as $[1,2,3,4,22,24,28,37,38,42,44,45,54,59,60]$ :

A) Future Internet network requirements (scalability, manageability, flexibility, reliability, resilience, robustness, security, latency, simplicity, etc.) and concepts (network virtualization, etc.) 
B) Future Internet routing methods, e.g. transport protocols, path selections;

C) Mobile networking technologies: mobility handling, fixed-mobile convergence (FMC), network concepts, 5G network infrastructures;

D) Future media networks, content-centric networks $(\mathrm{CCN})$, content delivery networks (CDN);

E) Network computing: ubiquitous, grid, cloud computing;

F) Virtual networks, software defined networks (SDN), network function virtualization (NFV);

G) Cloud infocommunications: NaaS, PaaS, SaaS, CaaS, etc.

\section{Chapter 4: Data and content technologies.}

The huge volumes of data and multimedia content are essential driving forces for the evolution of the Future Internet. These research topics aim at extracting meaning from data and supporting the collection, searching, managing and publishing of information in any form, as [2, 3, 11, 24, 47, 53]:

A) Data, text and media mining;

B) Big Data challenges (volume, velocity, variety) and solutions;

C) Semantic multimedia search methods, knowledge discovery;

D) Presentation, visualisation;

E) Digital library functions (archives, name spaces, etc.).

\section{Chapter 5: 3D Internet and cognitive infocommunications.}

The three dimensional (3D) communications can embrace our cognitive systems, including not only hearing and vision, but touch, gestures, emotion, smell, etc. Along with its enormous potential, 3D Internet opens many research challenges in order to become a reality, as $[5,9,13,14,15,16,17,19,27,46]$ :

A) 3D Internet architecture and content technology (3D media analytics, processing, presentation);

B) Multimodal human-computer interactions;

C) Cognitive infocommunications, cognitive contents and channels;

D) Virtual collaboration, 3D Internet based control and communications;

E) Devices and procedures of 3D and 4D content creation and presentation.

Chapter 6: Internet of Things (IoT).

Internet of Things is seen as a key part of the Future Internet vision, which targets real-time complex interactions and collaborations of billions of heterogeneous devices (objects, sensors, actuators), and requires tackling numerous 
technological, connectivity and interoperability issues $[1,2,3,4,33,40,62,52$, 56]:

A) IoT enabling technologies (RFID, NFC, etc.), sensors and actuators, energy and spectrum awareness;

B) Identification: naming, addressing, privacy awareness, IPv6-based IoT;

C) Communication architectures for constrained devices, IoT infrastructures, self-aware and organizing networks;

D) Data management, software solutions, security technologies: self-adaptive security mechanism and protocols, self-managed secure IoT;

E) Services support platforms, heterogeneous data collection and processing infrastructures.

Chapter 7: Cyber-physical systems and applications.

Cyber-physical systems refer to next generation embedded ICT systems that are interconnected and collaborate through the Internet of Things, and provide a wide range of innovative applications and services. Relevant research directions are [4, $25,34,41,43,61,52,56]$ :

A) Embedded and intelligent engineering systems;

B) Intelligent production applications, measuring and controlling physical processes;

C) Intelligent transport, cars and logistics;

D) Smart agriculture-food applications,

E) Smart energy systems, green ICT solutions.

Chapter 8: Future Internet community applications.

Users demand "always on" access to cheap, easy-to-use, secure, mobile, personalized and context-aware applications, which are to be realized over highly interconnected, increasingly complex infrastructures. The Internet of Things is implicated for smart environments and smart spaces. Several cross-disciplinary research challenges should be addressed [1, 2, 3, 4, 39, 52, 56, 61]:

A) Mobile crowd-sensing platform and functions;

B) Smart home and office applications;

C) Smart health and well-being applications;

D) Smart business applications;

E) Smart governance applications;

F) Smart city applications;

G) Other intelligent and cognitive community applications. 


\section{Chapter 9: Experimentation, standardization, regulation.}

Themes of this practical chapter embrace the requirements and design of comprehensive test facilities, the federation of test-beds, the technical and social experiments, the standardization activity as well as the emerging complex regulatory issues. The subchapters are defined as $[2,3,4,29,30,31,32,36,37$, 48, 56]:

A) Experimental systems, test-beds;

B) Experimental methods, demonstrations, field results;

C) Socio-economic studies, business models;

D) Technical standards, recommendations, standardization issues, e.g.: identification, communications, virtualization, interoperability, security;

E) Technical, economic and content regulatory issues.

\section{Conclusions}

This paper collects the challenges of the Current Internet, draws up Future Internet concepts and visions, and identifies the relevant functions and features of the Future Internet as of 2013. The Future Internet visions are based on a concept of unified infrastructure of communication, computing and storage resources by involving the Internet of people and content, devices and things, computers and clouds, and aim at objectives for the service, resource and content awareness, and the societal, economic and environmental awareness. The paper proposes a combined vision scheme with five objectives. The paper also defines the associated research goals and spheres, and clusters the research themes into nine research chapters and 52 subchapters. The identified research chapters are layered from basic research on Internet Science (Chapter 1), through applied research on Future Internet architectures and content engineering (Chapters 2-6) to Future Internet applications and experiments (Chapters 7-9). Within each chapter, the relevant research topics are organized into 5-7 subchapters.

\section{References}

[1] Towards the Future Internet - Emerging Trends from European Research, Future Internet Assembly 2010, Valencia, 15-16 April 2010, Edited by Tselentis, G. et al. ISBN 978-1-60750-538-9/539-6, 2010, IOS Press, Amsterdam

[2] The Future Internet - Future Internet Assembly 2011: Achievements and Technological Promises, Budapest, 17-19 May 2011, Edited by Dominigue, J. et al. LNCS 6656, ISBN 978-3-642-20898-0, 2011, Springer, Heidelberg

[3] The Future Internet - Future Internet Assembly 2012: From Promises to Reality, Aalborg, 9-11 May 2012, Edited by Alvarez, F. et al. LNCS 7281, ISBN 978-3-642-30240-4, 2012, Springer, Heidelberg 
[4] The Future Internet - Future Internet Assembly 2013: Validated Results and New Horizons, Dublin, 8-10 May 2013, Edited by Galis, A. and Gavras, A. LNCS 7858, ISBN 978-3-642-38081-5, 2013, Springer, Heidelberg

[5] Alpcan, T., Bauckhage, C. and Kotsovinos, E.: Towards 3D Internet: Why, What, and How? In International Conference on Cyberworlds, CW'07, pp. 95-99, 2007

[6] Alpcan, T., Buttyán, L. and J. S. Baras (eds.): Decision and Game Theory for Security, Lecture Notes in Computer Science, No. 6442, Springer 2010

[7] Bakonyi, P., Sallai, Gy.: Future Internet National Research Program JINKA2.1, in Hungarian, p. 55, Budapest, February 2014

[8] Barabási, A-L., Newman, M. and Watts, D. J.: The Structure and Dynamics of Networks, Princeton Studies in Complexity. ISBN 0-691-11357-2, Princeton University Press, 2006

[9] Baranyi P., Csapó A.: Definition and Synergies of Cognitive Infocommunications. Acta Polytechnica Hungarica, ISSN 1785-8860, Vol. 9, No. 1, 2012, pp. 67-83

[10] Bíró, J.: Novel Equivalent Capacity Approximation through Asymptotic Loss Analysis. Computer Communications. Special issue for Heterogeneous Networks: Performance Analysis and Traffic Engineering. 33:(1) pp. S152-S156. (2010)

[11] Boiko, B.: Content Management Bible. Wiley. p. 1176. Nov. 2004. ISBN 07645-7371-3

[12] Cerf, V. G.: The day the Internet age began. Nature 461 (7268): 1202 1203. 2009. doi:10.1038/4611202a. PMID 19865146

[13] CogInfoCom $2010 \quad\left(1^{\text {st }}\right.$ International Conf. on Cognitive Infocommunications), 29 Nov. - 1 Dec. 2010, Tokyo, Japan

[14] CogInfoCom $2011 \quad 2^{\text {nd }}$ International Conf. on Cognitive Infocommunications), 7-9 July 2011, Budapest, Hungary, Print-ISBN: 978$1-4577-1806-9$

[15] CogInfoCom $2012\left(3^{\text {rd }}\right.$ IEEEE International Conf. on Cognitive Infocommunications), 2-5 Dec. 2012, Kosice, Slovakia

[16] CogInfoCom 2013 (4 ${ }^{\text {th }}$ IEEE International Conference on Cognitive Infocommunications), Dec 2-6, 2013, Budapest, ISBN 978-1-4799-1-15439, In CogInfoCom2013: Workshop on Future Internet Science and Engineering

[17] Csapó A., Baranyi P.: An Interaction-Based Model for Auditory Substitution of Tactile Percepts. In: $14^{\text {th }}$ IEEE Int. Conference on Intelligent Engineering Systems (INES 2010) Paper 5483833. pp. 271-276. Las Palmas, Spain, 5-7- May 2010 
[18] Dányádi, Z., Földesi, P. and Kóczy, L. T.: Fuzzy Search Space for Correction of Cognitive Biases in Constructing Mathematical Models. In: $3^{\text {rd }}$ IEEE International Conference on Cognitive Infocommunications, Kosice, Slovakia, 2012, pp. 585-589

[19] Daras P. and Alvarez, F.: A Future Perspective on the 3D Media Internet. In: Towards the Future Internet - A European Research Perspective, Edited by Tselentis, G., et al. pp. 303-312, IOS Press, 2009. ISBN 978-1-60750007-0

[20] Do, V. T., Chakka, R., Sztrik, J.: Spectral Expansion Solution Methodology for QBD-M Processes and Applications in Future Internet Engineering. In: Nguyen N. T., Do V. T., Hoai A. T.: Advanced Computational Methods for Knowledge Engineering. Genova, Springer-Verlag, 2013, pp. 131-142

[21] European Commission: Green Paper on the Convergence of the Telecommunications, Media and Information Technology Sectors, and Implications for Regulation. Towards an Information Society Approach. 3 Dec. 1997, COM (1997) 623

[22] European Commission: Future Media Networks - Research Challenges 2010. Future Media Networks cluster of Networked Media Systems FP7 projects. 2010. ISBN 978-92-79-17393-6 doi:10.2759/37178

[23] European Commission: International Conference on Internet Science. The FP7 European Network of Excellence in Internet Science (http://internetscience.eu) Brussels, April 9-11, 2013

http://internetscienceconference.files.wordpress.com/2013/04/internet_scie nce_conference_proceedings.pdf

[24] European Commission: HORIZON 2020 - The Framework Programme for Research and Innovation. Brussels, 2011. Work Programme (2014-2020) 5.i. Leadership in enabling and industrial technologies: Information and Communication Technologies. Annex 6 to Decision. December 2013. p. 107

http://ec.europa.eu/research/horizon2020/pdf/work-programmes/ information_and_communication_technologies_draft_work_ programme.pdf

[25] Fischer, A., Beck, M. T., and de Meer, H.: An Approach to Energy-efficient Virtual Network Embeddings. In $5^{\text {th }}$ International Workshop on Management of the Future Internet (ManFI 2013) 2013. Google ScholarBibTex Fischer2013benergyefficient.pdf

[26] Földesi, P. and Botzheim, J.: Computational method for corrective mechanism of cognitive decision-making biases. In: $3^{\text {rd }}$ IEEE International Conference on Cognitive Infocommunications, Kosice, Slovakia, 2012, pp. 211-215 
[27] Galambos, P., Weidig, C., Baranyi, P., Aurich, J. C., Hammann, B., and Kreylos, O.: VirCA NET: A Case Study for Collaboration in Shared Virtual Space, in $3^{\text {rd }}$ IEEE International Conference on Cognitive Infocommunications, Kosice, Slovakia, 2012, No. 42, pp. 273-277

[28] Galis, A., Denazis, S., at al (eds.): Programmable Networks for IP Service Deployment, p. 450. Artech House Books. June 2004. ISBN 1-58053-745-6

[29] ITU-T Recommendation Y.3001: Future Network Vision - Objectives and Design Goals, 2011

[30] ITU-T Recommendation Y.3011: Framework of Network Virtualization for Future Networks, 2012

[31] ITU-T Recommendation Y.3021: Framework of Energy Saving for Future Networks, 2012

[32] ITU-T Recommendation Y.3031: Identification Framework in Future Networks, 2012

[33] Karnouskos, S., Skarmeta, A. F., et al: The Future Internet of Things. Introduction to Chapter on Internet of Things. In: The Future Internet Future Internet Assembly 2013: Validated Results and New Horizons. pp. xxv-xxvii. Springer, Heidelberg, 2013

[34] Lee, E. A. and Seshia, S. A.: Introduction to Embedded Systems - A CyberPhysical Systems Approach, http://LeeSeshia.org, 2011

[35] Lewis, Ted G.: Network Science: Theory and Applications, Wiley, March 11, 2009. ISBN 0-470-33188-7

[36] Liu, Yu-li (ed.): Convergence in the Digital Age. Special issue in Telecommunications Policy, pp. 611-685, Editorial pp. 611-614, ISSN 0308-5961, Vol. 37. No. 8, Sept. 2013, Elsevier, Amsterdam

[37] Matsubara, D., Egawa, T. et al: Open the Way to Future Networks - A Viewpoint Framework from ITU-T. In: The Future Internet - Future Internet Assembly 2013: Validated Results and New Horizons. pp. 27-38, 2013, Springer, Heidelberg

[38] Meer, H. de, Hummel, K. A. and Basmadjian, R. (eds.): Future Internet services and architectures: trends and visions. Special Issue in Telecommunication Systems, Vol. 51, No. 4, Dec. 2012, pp. 219-303

[39] Minutolo, A., Esposito, M., De Pietro, G.: Development and Customization of Individualized Mobile Healthcare Applications, in $3^{\text {rd }}$ IEEE Internat. Conf. on Cognitive Infocommunications, Kosice, Slovakia, 2012, No. 49, pp. 321-326

[40] Nishinaga, N.: NICT New-Generation Network Vision and Five Network Targets. IEICE Trans. on Communications, Vol. E93-B, No. 3, pp. 446449, March 2010, Online ISSN: 1745-1345, Print ISSN: 0916-8516 
[41] Nguyen, K. K., Cheriet, M., Lemay, M., et al: Renewable Energy Provisioning for ICT Services in a Future Internet: In: The Future Internet Future Internet Assembly 2011: Achievements and Technological Promises, pp. 419-429, Springer, Heidelberg, 2011

[42] Pallot, M., et al: A Tentative Design of a Future Internet Networking Domain Landscape. In: The Future Internet - Future Internet Assembly 2012: From Promises to Reality, pp. 237-249, 2012, Springer, Heidelberg

[43] Papadimitratos, P., La Fortelle, A., Evenssen, K., Brignolo, R. and Cosenza, S.: Vehicular Communication Systems: Enabling Technologies, Applications, and Future Outlook on Intelligent Transportation, IEEE Communications Magazine, Vol. 47, No. 11, pp. 84-95, 2009

[44] Papadimitriou, D., Zahariadis, T., et al: Design Principles for the Future Internet Architecture. In: The Future Internet - Future Internet Assembly 2012: From Promises to Reality, pp. 55-67, 2012, Springer, Heidelberg

[45] Petcu, D., Galis, A. et al: The Future Internet Cloud: Computing, Networking and Mobility. Introduction to Chapter on Computing and Networking Clouds. In: The Future Internet - Future Internet Assembly 2013: Validated Results and New Horizons. pp. xiii-xv. 2013, Springer, Heidelberg

[46] Prekopcsák, Z., Halácsy, P., Gáspár-Papanek, Cs.: Design and Development of an Everyday Hand Gesture Interface. In: $10^{\text {th }}$ Internat. Conf. on Human Computer Interaction with Mobile Devices and Services (Mobile HCI '08). Amsterdam, 2-5. Sept. 2008, ISBN: 978-1-59593-952-4 ACM, pp. 479-480, Paper PS479. New York

[47] Prekopcsák, Z., Makrai, G., Henk, T., Gáspár-Papanek, Cs.: Radoop: Analyzing Big Data with RapidMiner and Hadoop. In: RCOMM 2011: RapidMiner Community Meeting and Conference. Dublin, 8-9 June 2011, pp. $1-12$

[48] Sales, B., Darmois, E. et al: A Systematic Approach for Closing the Research to Standardization Gap. In: The Future Internet - Future Internet Assembly 2012: From Promises to Reality, pp. 18-29, Springer, Heidelberg, 2012

[49] Sallai, Gy.: Defining Infocommunications and Related Terms. Acta Polytechnica Hungarica, Vol. 9, No. 6, 2012, pp. 5-15

[50] Sallai, Gy.: From Telecommunications to Cognitive InfoCommunications and Internet of Things - Phases of Digital Convergence. In: $17^{\text {th }}$ IEEE Int. Conference on Intelligent Engineering Systems (INES 2013) ISBN 978-14799-0830-1, Paper 2. pp. 13-17, Costa Rica, 19-21 June 2013

[51] Sallai, Gy.: The FIRST Project and the Future Internet National Research Programme. Presentation. Future Internet PPP Workshop on Building an 
Eco-System for Delivering Innovative Future Internet Services and Applications. IEEE ICC 2013, Budapest, 13 June 2013

http://www.nih.gov.hu/nemzetkozi-tevekenyseg/jovo-internet/building-aneco-system

[52] Smith, Ian G. (ed): The Internet of Things 2012. New Horizons. IERC Internet of Things European Research Cluster, $3^{\text {rd }}$ edition of the Cluster Book. p. 360, Halifax, UK, 2012, ISBN: 978-0-9553707-9-3

http://www.internet-of-things-

research.eu/pdf/IERC_Cluster_Book_2012_WEB.pdf

[53] Szücs, G.: Decision Trees and Random Forest for Privacy-Preserving Data Mining. In: Tarnay, K., Imre, S., Lai Xu (ed.): Research and Development in E-Business through Service-oriented Solutions. IGI Global, Hershey, PA, USA, 2013, pp. 71-90, ISBN 978-1-4666-4181-5

[54] Stratogiannis, D., Tsiropoulos, G. et al (eds.): Mobile Computing and Networking Technologies. Special Issue in Telecommunication Systems, Vol. 52, No. 4, April 2013, pp. 1714-2145

[55] Tapolcai, J., Gulyás, A., Heszberger, Z., Biró, J., Babarczi, P., Trossen, D.: Stateless Multi-Stage Dissemination of Information: Source Routing Revisited. In: IEEE Globecom. Anaheim, USA, 3-7. Dec. 2012, pp. $2797-$ 2802

[56] Vermesan, O. and Friees, P. (eds.): Internet of Things - Converging Technologies for Smart Environments and Integrated Ecosystems p. 363, River Publishers, Aalborg, 2013, ISBN: 978-87-92982-96-4 (E-Book) http://www.internet-of-thingsresearch.eu/pdf/Converging_Technologies_for_Smart_Environments_and_I ntegrated_Ecosystems_IERC_Book_Open_Access_2013.pdf

[57] Wainwright, N., Papanikolaou, N.: The FIA Research Roadmap, Priorities for Future Internet Research. Introduction in: The Future Internet - Future Internet Assembly 2012: From Promises to Reality, pp. 1-5, 2012, Springer, Heidelberg

[58] World Economic Forum: Digital Ecosystem - Convergence between IT, Telecoms, Media and Entertainment: Scenarios to 2015, World Scenario Series, 2007

http://www3.weforum.org/docs/WEF_DigitalEcosystem_Scenario2015_Ex ecutiveSummary_2010.pdf

[59] Zahariadis, T. et al: Towards a Content-Centric Internet. In: Towards the Future Internet - Emerging Trends from European Research, Edited by Tselentis, G. et al. pp. 227-236, 2010, IOS Press, Amsterdam

[60] Zahariadis, T. et al: Towards a Future Internet Architecture. In: The Future Internet - Future Internet Assembly 2011: Achievements and Technological 
Promises, Edited by Dominigue, J. et al. pp. 7-18, 2011, Springer, Heidelberg

[61] Zeller, D., Olsson, M. et al: Sustainable Wireless Broadband Access to the Future Internet - The EARTH Project. In: The Future Internet - Future Internet Assembly 2013: Validated Results and New Horizons. pp. 249271, 2013, Springer, Heidelberg

[62] Ziegler, S., Crettaz, C. et al: IoT6 - Moving to IPv6-based Future IoT. In: The Future Internet - Future Internet Assembly 2013: Validated Results and New Horizons. pp. 161-172, 2013, Springer, Heidelberg 